\title{
PERFORMANCE EVALUATION OF SOLAR COOKER MADE
}

\section{FROM LOCALLY SOURCED MATERIALS}

\author{
S. D. ADEWUMI ${ }^{1}$, A. T. ABDULRAHIM ${ }^{1}$, A. A. ADELEKE ${ }^{1}$, \\ P. P. IKUBANNI ${ }^{2} \&$ O. O. AGBOOLA ${ }^{2}$ \\ ${ }^{I}$ Department of Mechanical Engineering, University of Ilorin, Ilorin, Omu-Aran, Nigeria \\ ${ }^{2}$ Department of Mechanical Engineering, College of Engineering, Landmark University, Omu-Aran, Nigeria
}

\begin{abstract}
This study describes the development and performance evaluation of a four reflector solar cooker, which was made from locally sourced materials. Teak wood was used in the construction of the solar box cooker with the dimension $500 \times 400 \times 300 \mathrm{~mm}$. The box was lagged, so as to reduce the rate of heat loss and increase the amount of heat generated for the cooking. Experiments were performed on the solar cooker with no reflector, one reflector, two reflectors, three reflectors and four reflectors. Results from the first figure of merits $\left(F_{1}\right)$ showed that the solar cooker with two, three and four reflectors are considered grade $A$ solar cooker. The second figure of merit $\left(F_{2}\right)$ condition was met only by the solar cooker with four reflectors with its value greater than 0.42 . The cooker thermal efficiency increases from 18.72 to $72.22 \%$ as the number of reflectors increases. The solar box cooker with four external reflectors was more efficient when compared with others and thus, can be used in cooking and drying of agricultural products.
\end{abstract}

KEYWORDS: Solar Cooker, Reflector, Figure of Merits, Thermal Efficiency \& Stagnation Point

Received: Oct 17, 2018; Accepted: Nov 07, 2018; Published: Feb 22, 2019; Paper Id.: IJMPERDAPR201929

\section{INTRODUCTION}

Cooking energy amounts to about $90 \%$ of the total energy consumption for most households in developing countries such as Nigeria [1, 2]. In rural areas, cooking energy is obtained through the usage of firewood and agricultural residues, because commercial fuels such as kerosene and cooking gas are not readily available. Specifically, fire wood remains the major fuel cooking energy being utilized by rural dwellers in spite of the various benefits that renewable energy such as the usage of solar energy offers [1]. It is of environmental concern that the continuous usage of firewood has caused the increase in rate of deforestation which has necessitated a high demand for energy sustainability from renewable sources such as the solar cookers. Solar cookers are devices that convert direct sunlight energy into heat which can be utilized for cooking and for some other processes such as pasteurization and sterilization [3]. Solar box cooker (SBC) is a thermal device that is very useful and readily available throughout the world. Few characteristics of SBC as a renewable energy thermal device are portability, user friendliness, easily operable, environmental friendly as air pollution is reduced and it is economical to obtain. A SBC is basically an insulated box with a transparent glass cover and a top lid which has a mirror booster on the inside to reflect sunlight into the box when the lid is kept open [4]. SBC is a very useful and popular thermal device which is available throughout the world. It is one of the few renewable energy thermal gadgets which are portable, user friendly, easily operable, meant to fulfill the very basic need and economically 
competitive. Its affordable price makes it very attractive commercially, especially among the rural populace in the developing countries. A reasonable interest has been shown by the scientists, from time to time, in proposing various parameters which can be considered as the measure of its thermal performance. According to Ohunakin et al. [5], Nigeria is located around the equator which is within a high sunshine belt of fairly well distributed solar radiation is fairly well distributed. Through estimation, it was stated that the annual daily average of total solar radiation varies from about 12.6 $\mathrm{MJ} / \mathrm{m}^{2} /$ day $\left(3.5 \mathrm{kWh} / \mathrm{m}^{2} /\right.$ day $)$ in the coastal region to about $25.2 \mathrm{MJ} / \mathrm{m}^{2} /$ day $\left(7.0 \mathrm{kWh} / \mathrm{m}^{2} /\right.$ day $)$ in the far north, thus making her to have an estimated 17,459,215.2 million MJ/day (17.439 TJ/day) of solar energy falling on its $923,768 \mathrm{~km}^{2}$ land area. No load and full load tests was conducted on SBC and two figures of merit (F1 and F2), which should serve as the measure of obtaining its thermal performance was recommended by Mullick et al. [2] and accepted by BIS 2000 [6] as the benchmark indicators of its thermal performance. Several research works have been carried out in recent past years in the world which clearly shows the utilization of solar energy as the greatest needs of mankind.

Adewole et al. [1] evaluated the performance of a four reflector based solar box cooker. The thermal performance of the cooker in terms of figures of merits and cooker efficiency were evaluated based on BIS 2000 [6]. Results show $67^{\circ} \mathrm{C}$ stagnation point at maximum isolation of $520 \mathrm{~W} / \mathrm{m}^{2}$ at $2.00 \mathrm{pm}$ and minimum of $246 \mathrm{w} / \mathrm{m}^{2}$ at $11.00 \mathrm{am}$. Theoretical and experimental investigation was carried out on a solar water sterilization system with thermally controlled flow by [7]. The effects of environmental conditions on the system's behaviour for the hot box solar cooker were carried out using the basic heat transfer analysis. Thermal and biological tests of the water samples during the sterilization process were obtained. In the work presented by [8], the overall heat transfer coefficients between the components of a solar box cooker were determined. This necessitated the work of Ozkaymak [9] in modeling the performance of a hot box solar cooker by using the coefficients determined and obtained by [8]. Mathematical model was presented for the performance of a novel hot box solar cooker developed by [10]. In the study, there was no agreement between theoretical and experimental results even with the usage of the geometric constants required for the solution to the 4th order Runge-Kutta method used in solving. A novel design of solar cooker in which, the absorber is exposed to solar radiation from the top and the bottom sides was developed; and theoretically and experimentally examined by [11]. In order to direct the radiation to the lower side of the absorber plate, a set of plane diffuse reflectors was utilized. Temperature variation of each part of the cooker for both steady and transients conditions were predicted using the general energy balance. Using this predicted values, comparison with measurements made under actual weather conditions were done. The effects of instrumentation error was investigated and analysed by Ishan [12] on the performance of SBC. Folaranmi [13] recorded a stagnation point of $119^{\circ} \mathrm{C}$ stagnation point at solar radiations $740.12 \mathrm{~W} / \mathrm{m}^{2}$ which occurred at $1.00 \mathrm{pm}$. A $f_{1} 0.11 \mathrm{Km}^{2} \mathrm{~W}^{-1}$ value of first figure of merit was obtained where the allowed standard first figure of merit value test greater than 0.12 is marked an A-grade cooker and those of lesser values are marked B-grade cooker by the Bureau of Indian Standard (BIS). Other studies on solar box cooker and dryer in Nigeria include [14 - 17] and many more.

This study describes the development and performance of a solar box cooker made from locally sourced materials with detachable reflection plates, which is capable of cooking and drying of agricultural products. The solar cooker grade was determined through the experiments performed from the figure of merits. The cooker thermal efficiency was determined when no reflector, one reflector, two reflectors, three reflectors and four reflectors were used. 


\section{MATERIALS AND METHOD}

\section{Description and Construction Procedures of the Solar Cooker}

The design and construction of a solar box cooker requires fewer technicalities. In this study, selected local materials were put together to develop a solar cooker. Teak, a popular hard wood with high stability, good strength, high resistant to decay and rot, containing natural polymer based cellulose was sliced to a thickness of $15 \mathrm{~mm}$ and joined to form a box with dimension $(500 \times 400 \times 300 \mathrm{~mm})$ and covered at the bottom. The inner walls of the outer box were lagged $20 \mathrm{~mm}$ wide round the box including the base with fibre-glass material to reduce the rate of heat loss. Plywood of thickness $10 \mathrm{~mm}$ was cut and joined together to form the inner box with a dimension of $400 \times 300 \times 200 \mathrm{~mm}$, tightly fixed to the insulated layer and inclined at angles $70^{\circ}$ and $110^{\circ}$ in order to reflect light and transmit heat to the cooking pot which is placed at the centre of the box. The inside of the box are lined round with the aluminium foil to aid reflection towards the centre of the cooker aperture. A $400 \times 300 \mathrm{~mm}$ aluminium plate, painted black was placed inside the box to absorb the heat inside the solar cooker. All radiations that enter the solar cooker are absorbed by the black plate and converted to heat for cooking. A transparent $4 \mathrm{~mm}$ glass was cut out and framed $400 \times 300 \mathrm{~mm}$ to cover the top of the box. This helps in trapping heat and helps to prevent convective heat loss. To prevent heat losses at the corners, the glass glazing is fixed tightly at the edges with a rubber lining. Four external reflectors of $10 \mathrm{~mm}$ thickness were hinged round the box with a leather skin, flexible but tough, which can allow the removal and replacement of the solar cooker reflectors. The longer sides of the solar cooker box were fixed with external reflector of size $500 \times 400 \mathrm{~mm}$ at opposite sides while the shorter sides were fixed with external reflector of size $400 \times 400 \mathrm{~mm}$ at opposite sides and placed at $70^{\circ}$ and $110^{\circ}$ tilt angles. This angle of inclination reflects a higher percentage of light rays into the solar box (Folaranmi, 2013). The surface of the external reflector is then covered round with aluminium foil with the aid of synthetic glue as the external reflecting surface. The isometric view of the solar cooker is as shown in Figure 1. Figure 2 (a - e) shows the constructed solar box cooker with no reflector, one reflector, two reflectors, three reflectors and four reflectors, respectively.

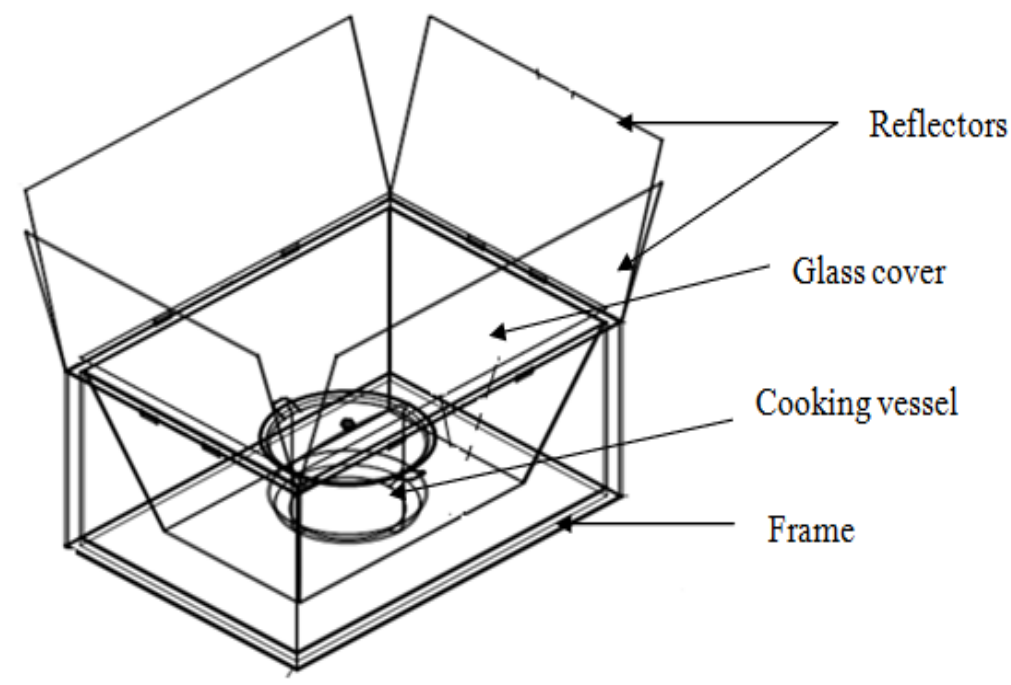

Figure 1: Isometric View of a Multiple Reflector Solar Cooker 


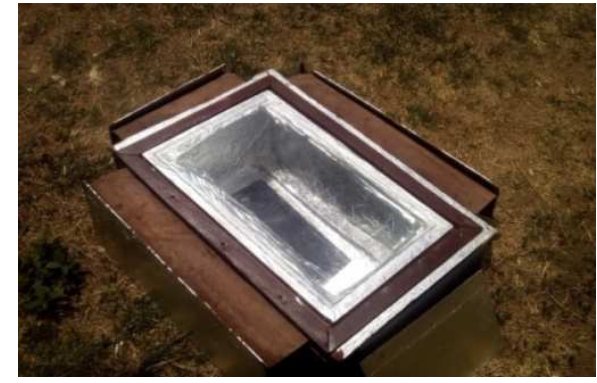

Figure 2(A): Cooker with No Reflector

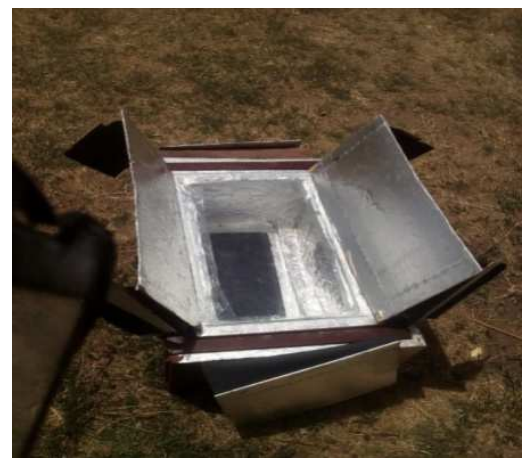

Figure 2(C): Cooker with Two Reflectors

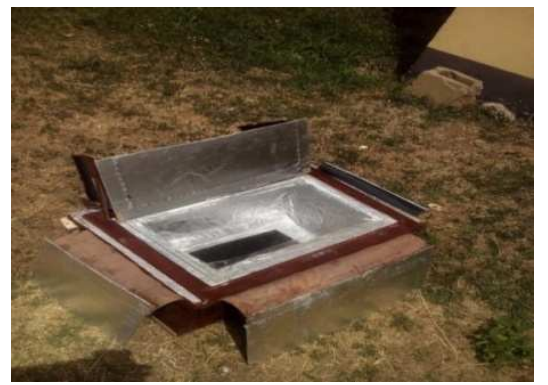

Figure 2(B): Cooker with One Reflector

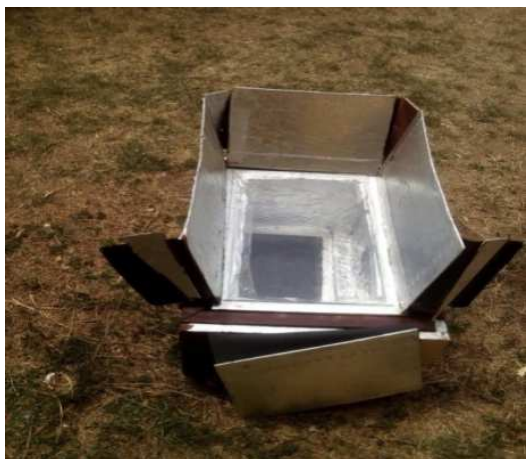

Figure 2(D): Cooker with Three Reflectors

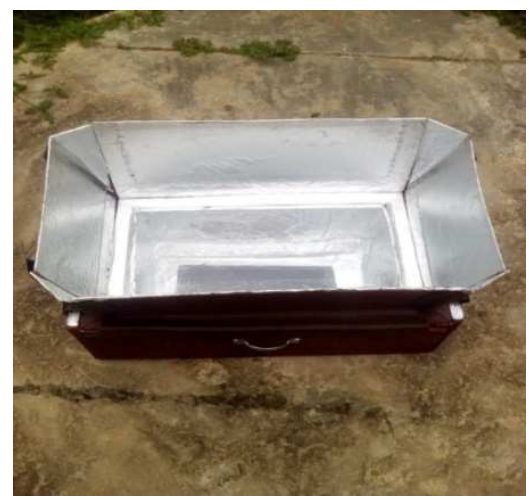

Figure 2(E):Cooker with Four Reflectors

\section{Design Calculations}

Maximum heat generated by the radiating black plate in the cooker was obtained using Eq. (1)

$$
\frac{Q_{T}}{\Delta t}=\in \sigma A\left(T_{f}^{4}-T_{i}^{4}\right)
$$

Where, $\in$ is the emissivity of a black body, $\sigma$ is the Stefan-Boltzmann constant $\left(\mathrm{W} / \mathrm{m}^{2} \mathrm{~K}^{4}\right)$, A is the surface area of the black body $\left(\mathrm{m}^{2}\right), \Delta T=\left(T_{f}-T_{i}\right)$, the temperature difference between the radiating body and the temperature of the surrounding $\left({ }^{\circ} \mathrm{C}\right), \Delta t$ is the time (s) $6 \mathrm{~h}(21600 \mathrm{sec}) Q_{T}$ is quantity of heat generated $(\mathrm{J})$

Eq (2) was utilized to determine the energy required to raise one litre of water to $100^{\circ} \mathrm{C}$

$$
Q=(M C)_{W} \Delta T
$$

Where, $\mathrm{Q}$ is quantity of heat, $\mathrm{M}$ is the mass of water, $\mathrm{C}$ is the specific heat capacity of water and $\Delta T$ is change in temperature between the ambient and desired temperature. 


\section{Experimental Procedure}

The experiment was carried out at the University of Ilorin, Ilorin environs ( $\left.8^{\circ} 30^{\prime} 0^{\prime \prime} \mathrm{N}, 4^{\circ} 32^{\prime} 60^{\prime \prime} \mathrm{E}\right)$. The readings were taken from 9 am to 6 pm within the month of February to June, 2017 (a total of 150 days in all). Each reading for a particular test was carried out in triplicate and the average was used.

\section{Stagnation Test at no Point Load Experiment (First Figure of Merit)}

The cooker is placed in the sun to receive solar radiation. Two thermocouples were utilized. One was to take the cooker's inner temperature $\left(\mathrm{T}_{\mathrm{c}}\right)$ and the other is to take the ambient temperature $\left(\mathrm{T}_{\mathrm{a}}\right)$. A corresponding solar radiation reading is taken alongside with a solar power meter. The connecting wires were kept intact to take the temperature readings. The stagnation temperature is ascertained from the reading and the first figure of merit was calculated using Eq. (3)

$$
F_{1}=\frac{\left(T_{C}-T_{a}\right)}{H_{S}}
$$

Where, $F_{1}$ is first figure of merit, $\mathrm{T}_{\mathrm{c}}$ is cooker temperature, $\mathrm{T}_{\mathrm{a}}$ is ambient temperature and $H_{s}$ is solar radiation.

\section{Sensible Heat Experiment Procedure (Second Figure of Merit)}

The cooker is preheated for 30 minutes to remove vapor inside the cooker which can limit the rate of the cooking performance. One litre of water is poured into the black pot and covered tightly. A thermocouple is used to take the cooker temperature $\left(\mathrm{T}_{\mathrm{c}}\right)$, the water temperature $\left(\mathrm{T}_{\mathrm{w}}\right)$ and the ambient temperature $\left(\mathrm{T}_{\mathrm{a}}\right)$ of the cooking environment. A corresponding solar intensity reading is taken alongside with a solar power meter. The door of the cooker is shut tightly to avoid outflow of heat energy from the cooker. The connecting wires were kept intact to take the temperature readings. The results from this experiment were used to evaluate the second figure of merit mathematically [18] using Eq. (4) as stated by [1].

$$
F_{2}=\frac{F_{1}(\mathrm{MC}) \mathrm{w}}{A \tau} \ln \left[\frac{\left[1-\frac{1}{F 1}\left(T_{w 2}-T_{a}\right)\right]}{\left[1-\frac{1}{F 1}\left(T_{w 1}-T_{a}\right)\right]}\right]
$$

Where, $F_{1}$ is first figure of merit $\left(\mathrm{Km}^{2} \mathrm{~W}^{-1}\right), \mathrm{Mw}$ is the mass of water as load $(\mathrm{kg}), \mathrm{C}_{\mathrm{w}}$ is the specific heat capacity of water $\left(\mathrm{J} / \mathrm{kg}^{\circ} \mathrm{C}\right), \mathrm{T}_{\mathrm{a}}$ is the average ambient temperature $\left({ }^{\circ} \mathrm{C}\right), \mathrm{H}$ is the average solar radiation incident on the aperture of the cooker $\left(\mathrm{W} / \mathrm{m}^{2}\right), \mathrm{Tw}_{1}$ is the initial water temperature $\left({ }^{\circ} \mathrm{C}\right), \mathrm{Tw}_{2}$ is the final water temperature $\left({ }^{\circ} \mathrm{C}\right)$, A is the aperture area $\left(\mathrm{m}^{2}\right)$ and $\mathrm{t}$ is the time difference between $\mathrm{Tw}_{1}$ and $\mathrm{Tw}_{2}(\mathrm{~s})$.

\section{Cooker Efficiency}

Mathematically, the overall thermal efficiency of the solar box cooker can be expressed in terms of the ratio of work output to work input as obtained using Eq. (5)

$$
\eta_{o=}^{\prime} \frac{M_{w} C_{w} \Delta T}{I_{a v A_{c} \Delta t}}
$$

Where, $\eta_{o}$ is overall thermal efficiency of the solar cooker, $M_{\mathrm{w}}$ is mass of water $(\mathrm{kg}), C_{\mathrm{w}}$ is specific heat capacity of water $(\mathrm{J} / \mathrm{kg} / \mathrm{K}), \Delta T$ is temperature difference between maximum temperature of water and the ambient temperature $\left({ }^{\circ} \mathrm{C}\right)$, $\mathrm{A}_{\mathrm{c}}$ is area of aperture of the cooker $\left(\mathrm{m}^{2}\right), \Delta t$ is time required to achieve the maximum temperature of cooking, $I_{\mathrm{av}}$ is Average solar intensity during the interval $\Delta \mathrm{t}\left(\mathrm{W} / \mathrm{m}^{2}\right)$ and $A_{c}$, the aperture area of the cooker. 


\section{RESULTS AND DISCUSSION}

\section{Stagnation Point}

Figure 3 shows the stagnation point when no reflector, one reflector, two reflectors, three reflectors and four reflectors were used at a corresponding value of solar intensity.

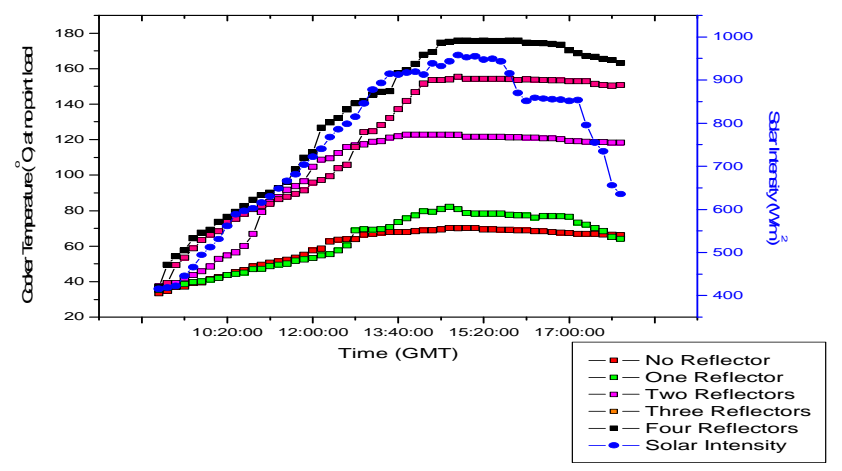

Figure 3: Stagnation Point Readings for a Multiple Solar Box Reflector

From Figure 3 increase in time of heating increases the temperature of the cooker when no reflector was used and when reflectors were used. It can also be deduced that solar intensity increases from around 9:40 am until between 1 and 3 pm which illustrates the reason for the increase in cooker temperature until around the said time, for all the experiments carried out using the different reflectors. However beyond $3 \mathrm{pm}$, the solar intensity began to reduce which was reflective on the cooker temperature reduction. Although water can be boiled using two, three and four reflectors, however, using four reflectors gave a very high cooker temperature of about $180^{\circ} \mathrm{C}$ when compared to others. This implies that using four reflectors was efficient and would easily boil water to $100^{\circ} \mathrm{C}$ and cook food. Water can only be warmed and not boiled at $100^{\circ} \mathrm{C}$ when no reflector and one reflector are utilized. This is because, water boils at $100^{\circ} \mathrm{C}$ and the cooker temperature could not reach $100^{\circ} \mathrm{C}$ for both conditions.

\section{First Figure of Merit}

Table 1 represents the results obtained for the first figure of Merit as evaluated using Eq. (3)

Table 1: No Point Load (First Figure of Merit)

\begin{tabular}{|l|c|c|c|c|}
\hline $\begin{array}{c}\text { Class of } \\
\text { Solar Cooker } \\
(\mathbf{A R})\left(\mathbf{m}^{2}\right)\end{array}$ & SP $\left({ }^{\circ} \mathrm{C}\right)$ & AT $\left({ }^{\circ} \mathrm{C}\right)$ & $\begin{array}{c}\text { SR } \\
\left(\mathbf{W} / \mathbf{m}^{2}\right)\end{array}$ & FFM $\left({ }^{\circ} \mathbf{C m}^{2} / \mathbf{W}\right)$ \\
\hline NR & 69.8 & 37.4 & 973.97 & 0.033 \\
\hline $1 \mathrm{R}(0.2)$ & 81.9 & 36.93 & 965.4 & 0.047 \\
\hline 2R $(0.36)$ & 122.7 & 35.93 & 955.93 & 0.091 \\
\hline 3R $(0.56)$ & 154.8 & 36.2 & 986.4 & 0.12 \\
\hline 4R $(0.72)$ & 175.7 & 37.7 & 974.5 & 0.142 \\
\hline
\end{tabular}

$* \mathrm{NR}$ is cooker with no reflector, ${ }^{*} \mathrm{AR}$ is area of reflector, $* 1 \mathrm{R}$ is cooker with one reflector, $* 2 \mathrm{R}$ is cooker with two reflectors, $* 3 \mathrm{R}$ is cooker with three reflectors $* 4 \mathrm{R}$ is cooker with four reflectors, $* \mathrm{SP}$ is stagnation point for the solar cooker, *AT is average ambient temperature (Ta), *SR is average solar radiation intensity and $* \mathrm{FFM}$ is first figure of merit. 
The stagnation point of the cookers increases while the solar radiation values are approximately within the same range for all the class of solar cooker reflectors. More energy is harnessed and stored as the numbers of external reflector are added. This leads to an increase in the value of the first figure of merits of the cooker types as the number of external reflectors increases. From Table 1, when the first figure of merit result was compared with the Bureau of Indian Standard (BIS) [6] for solar cooker having no reflector and that with one reflector, both classes of cooker are classified as grade B because $F_{1} \leq 0.09$ while those with first figure of merit $F_{1} \geq 0.91$ are classified as grade A solar cookers. Hence, the designed solar cooker with two, three and four external reflectors are classified as grade a solar cooker by the Bureau of Indian standard [6] and used in laboratories for drying of glass wears [19].

\section{Results of Sensible Heat Test (Second Figure of Merit)}

Table 2 represents the results obtained for boiling one litre of water with the solar box cookers.

Table 2: Boiling Time for one Litre of Water by the Solar Box Cooker

\begin{tabular}{|c|c|c|c|c|c|c|}
\hline $\mathbf{S} / \mathbf{N}$ & $\begin{array}{c}\text { Time } \\
(\mathbf{G M T})\end{array}$ & $\mathbf{N R}\left({ }^{\circ} \mathrm{C}\right)$ & $\mathbf{1 R}\left({ }^{\circ} \mathrm{C}\right)$ & $\mathbf{2 R}\left({ }^{\circ} \mathrm{C}\right)$ & $\mathbf{3 R}\left({ }^{\circ} \mathrm{C}\right)$ & $\mathbf{4 R}\left({ }^{\circ} \mathrm{C}\right)$ \\
\hline 1 & $12: 00$ & 30.4 & 30.6 & 30.5 & 30.5 & 30.4 \\
\hline 2 & $12: 10$ & 30.5 & 31.2 & 32.4 & 34.6 & 35.7 \\
\hline 3 & $12: 20$ & 30.8 & 31.5 & 39.8 & 40.8 & 42.8 \\
\hline 4 & $12: 30$ & 31.4 & 31.6 & 44.6 & 45.6 & 53.4 \\
\hline 5 & $12: 40$ & 31.7 & 33.5 & 48.4 & 50.4 & 60.8 \\
\hline 6 & $12: 50$ & 31.9 & 34.8 & 53.7 & 55.6 & 67.2 \\
\hline 7 & $13: 00$ & 32.1 & 36.2 & 55.8 & 59.1 & 75.1 \\
\hline 8 & $13: 10$ & 32.5 & 36.9 & 57.8 & 62.2 & 83.5 \\
\hline 9 & $13: 20$ & 32.7 & 38.2 & 59.6 & 65.6 & 89.2 \\
\hline 10 & $13: 30$ & 33.4 & 39.6 & 63.1 & 67.3 & 92.3 \\
\hline 11 & $13: 40$ & 35.6 & 40.4 & 65.9 & 70.6 & 96.7 \\
\hline 12 & $13: 50$ & 37.8 & 42.2 & 67.4 & 72.2 & 100 \\
\hline 13 & $14: 00$ & 39.2 & 43.8 & 69.8 & 75.4 & 100 \\
\hline 14 & $14: 10$ & 41.3 & 45.8 & 71.2 & 80.5 & 100 \\
\hline 15 & $14: 20$ & 42.6 & 49.5 & 73.5 & 85.3 & 100 \\
\hline 16 & $14: 30$ & 43.8 & 55.3 & 73.9 & 84.6 & 100 \\
\hline 17 & $14: 40$ & 45.1 & 59.7 & 74.5 & 84.5 & 100 \\
\hline 18 & $14: 50$ & 47.1 & 63.2 & 75.6 & 84.6 & 99.6 \\
\hline 19 & $15: 00$ & 48.6 & 66.1 & 75.6 & 84.5 & 99.5 \\
\hline 20 & $15: 10$ & 50.4 & 65.9 & 75.2 & 84.5 & 98.9 \\
\hline
\end{tabular}

$* \mathrm{NR}$ is cooker with no reflector, * $1 \mathrm{R}$ is cooker with one reflector, $* 2 \mathrm{R}$ is cooker with two reflectors, *3 is cooker with three reflectors and $* 4 \mathrm{R}$ is cooker with four reflectors.

At optimum hour (12:00 - 15:00 GMT), one litre of water was placed inside the cooker. It was observed that after $110 \mathrm{~min}$, cooker with four reflectors raised the temperature of one litre of water to its boiling point $\left(100^{\circ} \mathrm{C}\right)$; cooker with three reflectors raised one litre of water to $84.6^{\circ} \mathrm{C}$ after $160 \mathrm{~min}$, cooker with two reflectors; $75.6^{\circ} \mathrm{C}$ after $160 \mathrm{~min}$, cooker with a single reflector; $66.1^{\circ} \mathrm{C}$ after $180 \mathrm{~min}$ and cooker with no reflector; $50.4^{\circ} \mathrm{C}$ after 180 min. The results from the sensible heat test were used to evaluate the second figure of merit using Eq. (4) Table 3 represents the second figure of Merit (SFM) value obtained from sensible heat test for each class of solar cooker. 
Table 3: Evaluation of Second Figure of Merit

\begin{tabular}{|c|c|c|c|}
\hline S/N & $\begin{array}{c}\text { Class of Solar Cooker } \\
(\mathbf{A R})\left(\mathbf{m}^{\mathbf{2}}\right)\end{array}$ & $\Delta \boldsymbol{t}(\mathbf{m i n})$ & SFM \\
\hline 1 & $\mathrm{NR}$ & 185 & 0.262 \\
\hline 2 & 1R $(0.2)$ & 160 & 0.303 \\
\hline 3 & 2R $(0.36)$ & 145 & 0.334 \\
\hline 4 & 3R $(0.56)$ & 122 & 0.397 \\
\hline 5 & 4R $(0.72)$ & 110 & 0.44 \\
\hline
\end{tabular}

$* \mathrm{AR}$ is area of reflector, *NR is cooker with no reflector, * $1 \mathrm{R}$ is cooker with one reflector, $* 2 \mathrm{R}$ is cooker with two reflectors, $* 3 \mathrm{R}$ is cooker with three reflectors $* 4 \mathrm{R}$ is cooker with four reflectors and *SFM is second figure of merit.

It was observed that the values of second figure of merit increase as the number of reflectors increase. This is because, more solar radiations are trapped when solar cookers of higher number of reflectors are used. For solar cooker with no reflector, its second figure of merit is 0.262 , solar cooker with one reflector; 0.303, solar cooker with two reflectors; 0.334 , solar cooker with three reflectors; 0.397 and solar cooker with four reflectors; 0.440 . The criteria for $\mathrm{F}_{2}$ value by [6] is that $\mathrm{F}_{2}$ should be greater than $0.42\left(F_{1}>0.42\right)$. From this study, only the solar cooker with four external reflectors has a $F_{2}$ value (0.44) that is above the compared standard. Based on this value according to [1], solar cooker is suitable for utilization such as for boiling of water and drying of agricultural products. Therefore, the solar cooker with four reflectors will be useful for both water boiling and agricultural products.

\section{Overall Cooker Thermal Efficiency}

Table 4 represents the result of thermal efficiencies of solar cookers evaluated from the results obtained from the sensible heat test. The value for average solar intensity from the sensible heat test and average ambient temperature are 953.5 W/m $\mathrm{m}^{2}$ and $35.1^{\circ} \mathrm{C}$, respectively. The overall thermal efficiency was then evaluated using Eq. (5).

Table 4: Evaluation Cooker Thermal Efficiency

\begin{tabular}{|c|c|c|c|c|c|}
\hline S/N & $\begin{array}{c}\text { Class of Solar } \\
\text { Cooker }(\mathbf{A R})\left(\mathbf{m}^{\mathbf{2}}\right)\end{array}$ & HTW $\left({ }^{\circ} \mathrm{C}\right)$ & $\Delta \boldsymbol{t}(\mathbf{m i n})$ & $\Delta \boldsymbol{T}^{\circ} \mathrm{C}$ & $\begin{array}{c}\text { Overall } \\
\text { Efficiency }(\%)\end{array}$ \\
\hline 1 & $\mathrm{NR}$ & 50.4 & 185 & 15.3 & 18.72 \\
\hline 2 & 1R $(0.15)$ & 66.1 & 160 & 31 & 30.43 \\
\hline 3 & 2R $(0.2475)$ & 75.6 & 145 & 40.5 & 40.32 \\
\hline 4 & 3R $(0.3975)$ & 85.3 & 122 & 50.2 & 53.39 \\
\hline 5 & 4R $(0.495)$ & 100 & 110 & 64.9 & 72.22 \\
\hline
\end{tabular}

*HTW is the highest temperature reached of water during sensible heat test, $* \Delta T$ is the temperature difference between maximum temperature of water and the ambient temperature, $* \Delta t$ which is the time required achieving the maximum temperature of water, ${ }^{*} \mathrm{AR}$ is area of reflector, $* \mathrm{NR}$ is Cooker with no reflector, $* 1 \mathrm{R}$ is cooker with one reflector, $* 2 \mathrm{R}$ is cooker with two reflectors, $* 3 \mathrm{R}$ is cooker with three reflectors and $* 4 \mathrm{R}$ is cooker with four reflectors. 
Table 5: Relationship between the Figures of Merits and the BIS Grading System

\begin{tabular}{|c|c|c|c|c|c|}
\hline S/N & $\begin{array}{c}\text { Class of Solar } \\
\text { Cooker (AR) } \mathbf{~ m}^{\mathbf{2}}\end{array}$ & $\begin{array}{c}\text { FFM } \\
\left({ }^{\circ} \mathbf{C m}^{\mathbf{2}} / \mathbf{W}\right)\end{array}$ & SFM & EFF (\%) & BIS Grading \\
\hline 1 & NR & 0.033 & 0.262 & 18.72 & B \\
\hline 2 & 1R (0.15) & 0.047 & 0.303 & 30.43 & B \\
\hline 3 & 2R (0.2475) & 0.091 & 0.334 & 40.32 & B \\
\hline 4 & 3R (0.3975) & 0.12 & 0.397 & 53.39 & A \\
\hline 5 & 4R (0.495) & 0.142 & 0.44 & 72.22 & A \\
\hline
\end{tabular}

*AR is the area of reflector, FFM is first figure of merit, SFM is second figure of merit, EFF is overall efficiency, BIS is Bureau of Indian standard grading

The relationship between the figures of merits (first figure of merit and second figure of merit) and the Bureau of Indian Standard [6] grading system is as shown in Table 5.

The efficiency of the cooker increases with increase in number of reflectors from $18.72 \%$ to $72.22 \%$. Therefore, it can be established that solar performance of solar cooker increases with increase in number of external reflectors. In comparison with the efficiency of the solar cooker achieved in the study by Adewole et al. [1] which was 70.8\%, this present study achieved a better output of $72.22 \%$. It was observed that as the figures of merit increases, the efficiency of the cooker also improves from cooker with no reflector to cooker with four reflectors. Classification of solar box cooker based on the Bureau of Indian standard grading system shows that the cooker with three and four external reflectors with second figure of merit $\geq 0.39$ are graded A while those $\leq 0.39$ are graded B.

\section{Cooking and Drying Results}

Cooking test was performed using the solar cooker and the result obtained for the second figure of merit with solar cooker having four external reflectors shows that it can be used for cooking and drying. This agrees with the work of [1]. The result shows that, from $60^{\circ} \mathrm{C}$ of water, the time required to cook $120 \mathrm{~g}$ of noodles (indomie super pack) was 80 min, $150 \mathrm{~g}$ of rice cooked after $122 \mathrm{~min}$ and an egg of $55 \mathrm{~g}$ boiled in 90 minutes.

The solar cooker was utilized to dry cassava extract. Table 6 represents the result of the drying test on cassava extract. Cassava extracts, popularly known as starch, used in textile industry while packaging fabric are preserved by drying. A $14 \%$ moisture content of cassava extract was placed inside the solar cooker and under the direct sun for drying. The drying process was monitored and recorded until samples were dried.

Table 6: Result Obtained for Drying of Cassava Extract (Starch) of 14\% Moisture Content

\begin{tabular}{|c|c|c|c|c|c|}
\hline $\begin{array}{c}\text { Time } \\
\text { (GMT) }\end{array}$ & Duration (Min) & $\mathbf{T}_{\mathbf{a}}\left({ }^{\circ} \mathbf{C}\right)$ & $\mathbf{T}_{\mathbf{c}}\left({ }^{\circ} \mathbf{C}\right)$ & $\begin{array}{c}\text { Weight of Sample } \\
\text { in Sun }(\mathbf{g})\end{array}$ & $\begin{array}{c}\text { Weight of Sample in } \\
\text { the Solar Box }(\mathbf{g})\end{array}$ \\
\hline $12: 30$ & 0 & 32.3 & 63.7 & 300 & 300 \\
\hline $13: 00$ & 30 & 32.8 & 89.2 & 292 & 287 \\
\hline $13: 30$ & 60 & 34.5 & 123.7 & 273 & 244 \\
\hline $14: 00$ & 90 & 35.6 & 156.1 & 269 & 244 \\
\hline $14: 30$ & 120 & 36.1 & 170.3 & 258 & 244 \\
\hline $15: 00$ & 150 & 36.3 & 172.5 & 246 & \\
\hline
\end{tabular}

At optimum hour (12:30 to 15:00 GMT), the samples were observed from initial weight of $300 \mathrm{~g}$. After $90 \mathrm{~min}$, the sample in the solar box cooker dried at $156.1^{\circ} \mathrm{C}$ while that which was under direct sunlight dried after 150 min with 
presence of impurities. The rate at which the sample dried inside the cooker was faster compared with the rate at which it dried under direct sun. This may be as a result of more radiation that is focused into and attracted by the external reflectors of the solar cooker. Exposure of the sample to direct sun light opens the sample to interference of impurities. This could also have slowed down the rate of drying of the sample under direct sunlight. The enclosed system of the solar box cooker thus preserved samples from impurities hence, making it better and more preferred.

\section{CONCLUSIONS}

The design of solar box cooker with four external collectors and a base absorber suitable for cooking and drying was developed from locally available materials. The stagnation point for solar cooker with no reflector, one reflector, two reflectors, three reflectors and four reflectors are $69.8,81.9122 .7,154.8$ and $175.7^{\circ} \mathrm{C}$, respectively. With $175.7^{\circ} \mathrm{C}$ stagnation point of solar box cooker with four external reflectors, warming of water, food and removal of moisture from wet samples were achievable. The first figure and second figure of merits increased from $0.033^{\circ} \mathrm{Cm} 2 / \mathrm{W}$ to $0.142^{\circ} \mathrm{Cm} 2 / \mathrm{W}$ and from 0.262 to 0.44 , respectively. The performance test indicated that solar cooker with higher number of reflectors performs better than those with lower number or no reflector. The efficiency of the cooker increases as the number of external reflectors increase from 18.72 to $72.22 \%$. Cooker with four external reflectors has the best efficiency. The designed solar box was able to boil water, egg, cook rice, noodles and dries a $14 \%$ moisture content of cassava extract.

\section{REFERENCES}

1. Adewole, B. Z., Popoola, O. T. \& Asere, A. A. (2015). Thermal Performance of a Reflector Based Solar Box Cooker Implemented in Ile-Ife, Nigeria, International Journal of Energy Engineering5(5), 95-101.

2. Mullick, S. C., Kandpal, T. C. \& Subodh, K. (1996). Testing of box-type, Solar cooker: second figure of merit F2 and its variation with load and number of pots, Solar Energy, 57(5), 409-413.

3. Ali, S. A., Mohammed, S. A. \& Saleh, A. A. (2018). Design and Development of a Solar-Based Cooker with a Mechanical Sun Tracking System, International Journal of Ambient Energy. (in press).

4. Saxena, A., Varun, B., Pandey, S.P. \& Srivastav, G. (2011). A thermodynamic review on solar box type cookers, Renewable and Sustainable Energy Reviews, 15, 3301-3318.

5. Ohunakin, O. S., Adaramola, M. S., Oyewola, O. M. \& Fagbenle, R. O. (2014). Solar energy applications and development in Nigeria: Drivers and barriers, Renewable and Sustainable Energy Reviews, 32, 294-301.

6. Bureau of Indian Standards (BIS) 2000. IS 13429 (part 3) (2000): Indian standards solar e box type e specification part 3 test method (first revision). New Delhi.

7. Saitoh, T. S. \& El-Ghetany, H. H. (1999). Solar water-sterilization system with thermally controlled flow, Applied Energy, 64, $387-399$.

8. El-Sebaii, A. A. \& Aboul-Enein, S. (1997) A box-type solar cooker with one-step outer reflector, Energy, 22, 515-524.

9. Ozkaymak, M. (2007). Theoretical and experimental investigation of a hot box-type solar cooker performance, P I Mech Eng A-J Pow, 221, $91-97$.

10. Kumar, R., Pedgopu, V., Kumar, A. N. I. L., Thakur, R. O. B. I. N., \& Pundir, A. N. I. L. (2013). CFD based analysis heat transfer and friction characteristics of broken multiple rib roughened solar air heater duct. Int J Mech Prod Eng Res Dev, 3, 165-172. 
11. Binark, A. K. \& Turkmen, N. (1996). Modelling of a hot box solar cooker, Energy Conversion Management, 37, pp. 303-310.

12. Amer, E. H. (2003). Theoretical and experimental assessment of a double exposure solar cooker, Energy Conversion Management, 44, $2651-2663$.

13. Ishan, P. (2010). Testing of solar cookers and evaluation of instrumentation error, Renewable Energy, 35, 2053-2064.

14. Folaranmi, J. (2013). Performance Evaluation of a Double Glazed Box-Type Solar Oven with Reflector, Journal of Renewable Energy, doi.org/10.1155/2013/184352, 1-8.

15. Ekechukwu, O. V. \& Ugwuoke, N. T. (2003). Design and measure performance of a plane reflector augmented box-type solar energy cooker, Renewable Energy, 28, 1935-1952.

16. Kassem, T. K., Alosaimy, A., Fazian, M., \& Hamed, A. M. (2013). Development of the solar kilns used in drying the palm trees waste in Saudi Arabia. Int. J. Mech. Eng, 2(2), 43-50.

17. Akinoso, R. \& Aremu, A. K. (2103). Potential use of box type solar cooker in developing countries, The Journal of the Association of Professional Engineers of Trinidad and Tobago, 41(1), 11-17.

18. M. A. Ayoola, L. A. Sunmonu, M. I. Bashiru and O. O. Jegede, "Measurement of net all-wave radiation at a tropical location, Ile-Ife, Nigeria," Atmósfera, vol. 27(3), pp. 305-315, 2014.

19. Kolawole, A., Ikubanni, P. P., Agboola, O. O. \& Anifowose, O. B. (2018). Development and Performance Evaluation of an Economic Solar Grain Dryer, International Journal of Mechanical Engineering and Technology, 9(10), 589-604.

20. Mohod, A. G \& Powar, A. G. (2011). Development and evaluation of multi reflector foldable type solar cooker, Agricultural Engineering International: CIGR Journal, 13(1).

21. Rashid, F., Dawood, K., \& Hashim, A. H. M. E. D. (2014). Maximizing of solar absorption by (TiO2-water) nanofluid with glass mixture. International Journal of Research in Engineering \& Technology, 2, 87-90.

22. Negi, B. S. \& Purohit, I. (2005). Experimental investigation of a box type solar cooker employing a non-tracking concentrator, Energy Conversion and Management, 46, 577-604. 
